\section{Kidney \\ Blood Pressure \\ Research}

Kidney Blood Press Res 2014;39:507-515

DOI: 10.1159/000368461

Published onine: November 28, 2014

(C) 2014 S. Karger AG, Basel

www.karger.com/kbr

Accepted: July 18, 2014

$1423-0143 / 14 / 0396-0507 \$ 39.50 / 0$

This is an Open Access article licensed under the terms of the Creative Commons AttributionNonCommercial 3.0 Unported license (CC BY-NC) (www.karger.com/OA-license), applicable to

the online version of the article only. Distribution permitted for non-commercial purposes only.

\title{
Bone Metabolism and Arterial Stiffness After Renal Transplantation
}

\author{
Orsolya Cseprekála,b Eva Kis ${ }^{a}$ Arianna A. Dégia Andrea Kertia Attila J. Szabóa \\ György S. Reusz ${ }^{a}$
}

a1st Department of Pediatrics; ${ }^{b} 1$ st Department of Internal Medicine, Semmelweis University, Budapest, Hungary

\section{Key Words}

Chronic kidney disease - Transplantation $\cdot$ Bone turnover $\cdot$ Metabolic bone disease $\cdot$ Arterial stiffness

\begin{abstract}
Background/Aims: To assess the relationship between bone and vascular disease and its changes over time after renal transplantation. Metabolic bone disease (MBD) is common in chronic kidney disease (CKD) and is associated with cardiovascular (CV) disease. Following transplantation (Tx), improvement in CV disease has been reported; however, data regarding changes in bone disease remain controversial. Methods: Bone turnover and arterial stiffness (pulse wave velocity (PWV)) were assessed in 47 Tx patients (38 (3-191) months after Tx). Results: Bone alkaline phosphatase (BALP), osteocalcin (OC) and beta-crosslaps were significantly higher in Tx patients, and decreased significantly after one year. There was a negative correlation between BALP, OC and steroid administered ( $r=-0.35 ; r=-0.36$ respectively). PWV increased in the Tx group (1.15 SD). In patients with a follow up of $<24$ months, PWV was correlated with BALP and beta-crosslaps ( $r=0.53 ; r=0.69$ respectively) while in the $\geq 24$ months group, PWV was correlated with cholesterol $(r=0.38)$. Conclusions: Increased bone turnover and arterial stiffness are present following kidney transplantation. While bone turnover decreases with time, arterial stiffness correlates initially with bone turnover, after which the influence of cholesterol becomes significant. Non-invasive estimation of bone metabolism and arterial stiffness may help to assess CKD-MBD following renal transplantation.
\end{abstract}

Copyright $(2014$ S. Karger AG, Basel

O. Cseprekál and E. Kis have equally contributed to the manuscript and therefore share first authorship

György S Reusz MD, PhD

First Department of Pediatrics, Semmelweis University Budapest, Bókay János Str. 53. H-1083 Budapest (Hungary), Tel. +36-30-9869545, Fax +36-1-3247795

E-Mail reusz.gyorgy@med.semmelweis-univ.hu 


\section{Kidney \\ Blood Pressure Research}

Kidney Blood Press Res 2014;39:507-515

\begin{tabular}{l|l}
\hline DOI: $10.1159 / 000368461$ & C 2014 S. Karger AG, Basel
\end{tabular}

Publisnea onIIne: November 28, 2014

www.karger.com/kbr

508

\section{Introduction}

Abnormalities in bone and mineral metabolism are common complications in chronic kidney disease (CKD) patients [1]. These abnormalities are associated with cardiovascular (CV) disease according to recent evidence [2-4]. Chronic kidney disease-mineral bone disorder (CKD-MBD) has been suggested as a non-traditional risk factor in explaining the high rates of CVD in CKD patients [5, 6].

Renal transplantation is the optimal treatment in patients with end stage renal disease as it may correct most uremic metabolic alterations. Accordingly, improvement in uremic CV disease following renal transplantation has been reported; however, data on improvement of bone disease are somewhat controversial [7-9].

Assessing bone turnover is an important diagnostic tool in the management of renal bone disease. Given the invasive nature of the "gold standard" bone biopsy procedure, biomarkers are used to evaluate and monitor bone turnover [10]. There is however little information regarding bone metabolism and its relation to arterial elasticity in children following renal transplantation (Tx).

In a previous study, we had shown an increased bone turnover in patients following renal transplantation even with relatively well-preserved bone mineral density [11]. On the other hand, in another study evaluating arterial stiffness in children with Tx, we were able to show that following successful Tx, pulse wave velocity (PWV), a marker of arterial stiffness [12], was lower than in dialyzed patients, which could imply that vascular changes in children are reversible [13].

Post-transplant bone metabolism reflects both the effects of previous CKD-MBD persisting after transplantation and remodelling after correction of the metabolic effects of CKD [14]. During the first years post-transplantation, catch-up growth and bone remodelling predominates, with normalization of bone turnover later on. Thus the contribution of each component to the overall presentation changes over time.

The aim of the present study was to evaluate the relationship between bone and vascular disease and its change over time after transplantation onward. Using non-invasive parameters, we assessed bone turnover and arterial stiffness in renal transplant children with stable graft function (CKD 1-3).

\section{Patients and Methods}

Forty-seven transplanted patients (aged 15.5 (4.6) years, 32 males) were examined. The time spent on dialysis prior to Tx was 11 (0-61) months while the elapsed time since transplantation was 38 (3-191) months [median (range)].

Anthropometric, blood pressure and PWV data of the patients are shown in Table 1.

The diagnoses leading to end-stage renal disease (ESRD) were (number of patients in parentheses): renal hypoplasia, obstructive uropathy (16), focal segmental glomerulosclerosis (8), cystic renal disease (6), Alport syndrome (3), cystinosis (2), systemic lupus erythemotosus (2), acute tubular necrosis (1), Prune Belly syndrome (1), nephrocalcinosis (1), other syndromes (VACTERL, Joubert, Barakat, acrorenal) (4), unknown origin (3).
Table 1. Anthropometric and clinical characteristics of renal transplant patients

\begin{tabular}{lc}
\hline & $\begin{array}{c}\text { Renal } \\
\text { transplant } \\
\text { patients }\end{array}$ \\
\hline Age (years) & $15.5(4.6)$ \\
Height (cm) & $153(18)$ \\
Weight (kg) & $52.5(16.8)$ \\
BMI (kg/m²) & $21.8(4.5)$ \\
Systolic BP SDS & $0.96(0.94)$ \\
Diastolic BP SDS & $0.52(0.80)$ \\
Heart rate (1/min) & $75(14)$ \\
PWV & $5.69(0.95)$ \\
PWV SDS & $1.15(1.65)$ \\
\hline BMI: body mass index; BP: blood \\
pressure; SDS: tandard deviation \\
score; WV: pulse wave velocity \\
\hline
\end{tabular}




\section{Kidney \\ Blood Pressure Research}

The diagnosis of hypertension was based on $24 \mathrm{~h}$ ambulatory blood pressure measurement (ABPM); Z scores of systolic and diastolic BP (SBP and DBP) were used according to Soergel et al [15]. Hypertension was defined as SBP and/ or DBP equal or exceeding the 95th percentile for height.
Kidney Blood Press Res 2014;39:507-515

\begin{tabular}{l|l}
\hline DOI: 10.1159/000368461 & (c) 2014 S. Karger AG, Basel
\end{tabular}

Publisnea onIIne: November 28, 2014

www.karger.com/kbr

seprekál/Kis/Dégi/Kerti/Szabó/Reusz: Bone Metabolism and Arterial Stiffness After Renal Transplantation

Table 2. Distribution of patients with a follow-up $<24$ months and $\geq 24$ months

\begin{tabular}{lcc}
\hline & $\begin{array}{c}\text { Transplant patients } \\
<24 \text { months after Tx } \\
(\mathrm{n}=13)\end{array}$ & $\begin{array}{c}\text { Transplant patients } \\
\geq 24 \text { months after Tx } \\
(\mathrm{n}=34)\end{array}$ \\
\hline Age (years) & $12.9(4.5)$ & $16.4(4.4)^{*}$ \\
Weight $(\mathrm{kg})$ & $44.1(19.9)$ & $55.7(14.5)^{*}$ \\
Height $(\mathrm{cm})$ & $143(25)$ & $157(14)^{*}$ \\
Time after Tx (months) & $12.2(5.5)$ & $63.2(43.3)^{*}$ \\
\hline${ }^{*} \mathrm{p}<0.05 ;$ Tx transplantation & & \\
\hline
\end{tabular}

Eight children were normotensive while thirty nine patients received antihypertensive treatment. Thirteen patients received calcium channel blocker (amlodipine) or angiotensin converting enzyme inhibitor (enalapril or ramipril). Twenty six patients received combination therapy (ACE inhibitor and betablocker (metoprolol) and/or $\alpha 1$ blocker (prazosin).

With regard to immunosuppressive treatment, basic immunosuppressive therapy included tacrolimus (40 patients) or cyclosporine (7 patients) and mycophenolate mofetil (47 patients); twenty-two patients received steroid therapy at the time of PWV measurement.

Native Vitamin D3 supplementation (1000 IU/day) was administered routinely to all patients.

As patients suffered from mild dyslipidemia only we did not use specific lipid lowering treamtment (statins) other than diet in the study population.

\section{PWV measurement}

Aortic PWV was measured by applanation tonometry (PulsePen device, DiaTecne, Milan, Italy) [16] using sequential recordings of the arterial pressure wave at the carotid and femoral arteries, and by measuring the distance between the carotid sampling site to the suprasternal notch and from the suprasternal notch to the femoral sampling site, as described previously [13]. All measurements were performed twice to confirm reproducibility. Recordings with $>10 \%$ systolic or diastolic variability or $<80 \mathrm{mV}$ amplitude of the pulse wave signal were discarded. All measurements were performed by OC and EK.

PWV was expressed as PWV-Z score according to Reusz et al [17].

\section{Laboratory data}

Blood samples were collected at the timed control evaluations. Serum Ca, phosphate and creatinine were measured by routine laboratory methods. Jaffe's kinetic method was used for creatinine measurements. Creatinine clearance $(\mathrm{CCl})$ was calculated according to Schwartz et al [18].

Intact parathyroid hormone (PTH) (1-84) was determined by an immunochemiluminometric two-site assay (CIBA-CORNING, Frenwald, Germany).

Serum level of bone alkaline phosphatase (BALP) was measured by HYDRAGEL 15 ISO-PAL reagent, using the HYDRASIS (Issy-les-Moulineaux, France) system. Serum beta-crosslap level was determined by electrochemiluminescence immunoassay (ECLIA) on a Roche Elecsys 2010 immunoassay analyser (Mannheim, Germany).

Control group for bone markers: leftover serum samples of 47 patients matched for age, gender and pubertal stage (according to Tanner) and assessed for minor surgical interventions were used anonymously as controls for bone markers.

\section{Effect of time since transplantation}

To evaluate the effect of time since transplantation, patients were divided into two groups: those with a follow-up of less than 24 months, and those with a follow up of 24 months or longer. Thirteen out of the 47 patients were followed for $<24$ months (Table 2.)

Fourteen patients participating in this study had already been assessed in a previous study evaluating renal bone disease [19]. These patients had one-year follow-up data on bone markers (BALP, osteocalcin (OC), beta-crosslaps). 


\section{Kidney Blood Pressure Research}

\begin{tabular}{l|l}
\hline Kidney Blood Press Res 2014;39:507-515 \\
\hline DOI: $10.1159 / 000368461$ & $\begin{array}{l}\text { C } 2014 \text { S. Karger AG, Basel } \\
\text { www.karger.com/kbr }\end{array}$ \\
\hline Publisned onllne: November 28, 2014 &
\end{tabular}

To overcome the problem of the change in bone markers with age in the individual patient, paired data was normalized using the individual patient's values with those from matched controls according to the following formula:

normalised bone marker level = bone marker level / age- and gender-matched control bone marker level

Statistical analysis Database analysis was performed using STATISTICA 8.0 software (Stat Soft., Inc. USA). Data are presented as mean \pm standard deviation (SD) unless indicated otherwise. In case of data with non-normal distribution, data are expressed as median (range). As the distribution of the bone markers was skewed, logarithmic transformation was used to normalise the data for further statistical analysis. Laboratory data were compared by Student's t test or analysis of variance (ANOVA), where appropriate; the Mann-Whitney U test was used to compare data with non-normal distribution. Univariate regression analysis was applied to assess associations between laboratory data. The factors influencing PWV were assessed by standard and forward multiple regression analysis. A p value of $<0.05$ was considered statistically significant.

Ethics

The study was in accordance with the Helsinki declaration and was approved by the local ethics committee. Parental informed consent was obtained for all subjects participating in the study.

\section{Results}

Data on creatinine clearance, lipids and bone metabolism markers are summarized in Table 3.

Renal transplant children could be classified according to their $\mathrm{CCl}$ (numbers of patients in parentheses) CKD 1 (22), CKD 2 (23), CKD 3 (2).

$\mathrm{Ca}$ and $\mathrm{P}$ values of transplant patients were in the normal range. PTH values were under $60 \mathrm{pg} / \mathrm{ml}$ in 30 patients and under $120 \mathrm{pg} / \mathrm{ml}$ in 42 patients. BALP, OC and beta-crosslaps were significantly higher in transplanted children. As the distribution of the bone markers was skewed, logarithmic transformation was used for further statistical evaluation. The correlations between PTH and studied bone markers are shown in Table 4.

There was a negative correlation between BALP, OC and the (daily) steroid dose administered during the last year prior to the present evaluation (average of doses taken during the regular visits/year, expressed in $\mathrm{mg} /$ day) (Figure 1.). ( $\mathrm{r}=-0.35$ and $\mathrm{r}=-0.36$, both $\mathrm{p}<0.01$ ).
Table 3. Creatinine clearance, lipid levels and bone metabolism markers in renal transplant and control groups

\begin{tabular}{lcc}
\hline & $\begin{array}{c}\text { Transplant patients } \\
(\mathrm{n}=47)\end{array}$ & $\begin{array}{c}\text { Control } \\
(\mathrm{n}=47)\end{array}$ \\
\hline Creatinine clearance $\left(\mathrm{ml} / \mathrm{min} / 1.73 \mathrm{~m}^{2}\right)$ & $92.9(24.8)$ & $>90 \#$ \\
Ca $(\mathrm{mmol} / \mathrm{l})$ & $2.37(0.22)$ & $2.3-2.6 \#$ \\
P (mmol/l) & $1.36(0.29)$ & $1.16-1.67 \#$ \\
Cholesterol (mmol/l) & $4.22(1.45)$ & $3.0-5.0 \#$ \\
Triglycerides (mmol/l) & $1.96(1.41)$ & $0.5-2.0 \#$ \\
iPTH (pg/ml) & $49(8-190)$ & $10-65 \#$ \\
ln iPTH & $3.95(0.56)$ & $2.3-4.17 \#$ \\
Bone alkaline phosphatase -BALP (U/l) & $251(51-1460)^{*}$ & $213(68-488)$ \\
ln BALP & $5.56(0.73)^{*}$ & $5.23(0.61)$ \\
Osteocalcin - OC (ng/ml) & $110(27-1843)^{*}$ & $49(12-1470)$ \\
ln OC & $4.71(0.85)^{*}$ & $4.11(0.84)$ \\
beta-crosslaps (pg/ml) & $1354(79-3283)^{*}$ & $816(48-2345)$ \\
ln beta-crosslaps & $7.11(0.74)^{*}$ & $6.59(0.72)$ \\
PWV (m/s) & $5.69(0.95)$ & $5.11(0.71) \# \#$ \\
PWV - Z & $1.15(1.65) \# \#$ & NA \\
\hline \# Paediatric laboratory reference values; \#\#PWV reference values from Reusz et \\
al.[17]; NA: not applicable; P: phosphates; iPTH: intact parathyroid hormone; PWV: \\
pulse wave velocity; ln: natural logarithm; *p <0.05 Transplant vs. control \\
\hline
\end{tabular}




\section{Kidney Blood Pressure Research}

Effect of time since transplantation

The transplant patient group was divided into those with a follow-up of less than 24 months, and those with a follow-up of 24 months or longer (Table 2.).

The patients with the shorter follow-up were younger and had a shorter time since transplantation. The only significant metabolic difference between the two groups was a higher cholesterol level in patients with a longer interval time since transplantation (3.44 (1.45) versus $4.52 \quad$ (1.35) $\mathrm{mmol} / \mathrm{l}, \mathrm{p}<0.05)$. There was no significant difference between the groups in any of the other parameters studied (Ca, P, creatinine, $\mathrm{CCl}$, iPTH, and BALP, OC, beta-crosslaps corrected for age)

Pulse wave velocity in the renal transplant group

PWV was elevated by 1.15 SD in the Tx group. There was no correlation between PWV and bone markers and cholesterol for the transplanted group as a whole. However, in patients with a follow up of $<24$ months, PWV correlated with BALP and beta-crosslaps (BALP: $r=0.53 ; \quad p<0.05$ and betacrosslaps: $r=0.69 ; \quad p=0.01$ ). In multiple regression analysis, $ß$-crosslaps was the determinant factor of PWV (beta $=0.57, \mathrm{p}<0.03$ ).

In patients who were transplanted $\geq 24$ months before, PWV was correlated with cholesterol ( $\mathrm{r}=0.38$; p <0.05). (Figure 2). There was no correlation between PWV and any of the bone markers in this subgroup.
Kidney Blood Press Res 2014;39:507-515 \begin{tabular}{l|l}
\hline DOI: $10.1159 / 000368461$ & $\begin{array}{l}\text { C) 2014 S. Karger AG, Basel } \\
\text { www.karger.com/kbr }\end{array}$ \\
Published onlIne: November 28, 2014 & wworgen
\end{tabular}

Published onIIne: November 28, 2014

Cseprekál/Kis/Dégi/Kerti/Szabó/Reusz: Bone Metabolism and Arterial Stiffness After Renal Transplantation

Table 4. Correlations between PTH and studied bone markers (BALP, OC, beta-crosslaps)

\begin{tabular}{lcccc}
\hline & $\ln$ PTH & $\ln$ BALP & $\ln$ OC & $\begin{array}{c}\text { In beta- } \\
\text { crosslaps }\end{array}$ \\
\hline ln PTH & 1 & $0.49^{*}$ & $0.45^{*}$ & $0.29^{*}$ \\
$\ln$ BALP & $0.49^{*}$ & 1 & $0.65^{*}$ & $0.59^{*}$ \\
ln OC & $0.45^{*}$ & $0.65^{*}$ & 1 & $0.35^{*}$ \\
ln beta-crosslaps & $0.29^{*}$ & $0.59^{*}$ & $0.35^{*}$ & 1 \\
\hline
\end{tabular}

*p <0.05; PTH: parathyroid hormone, BALP: bone alkaline phosphatase; OC: osteocalcin

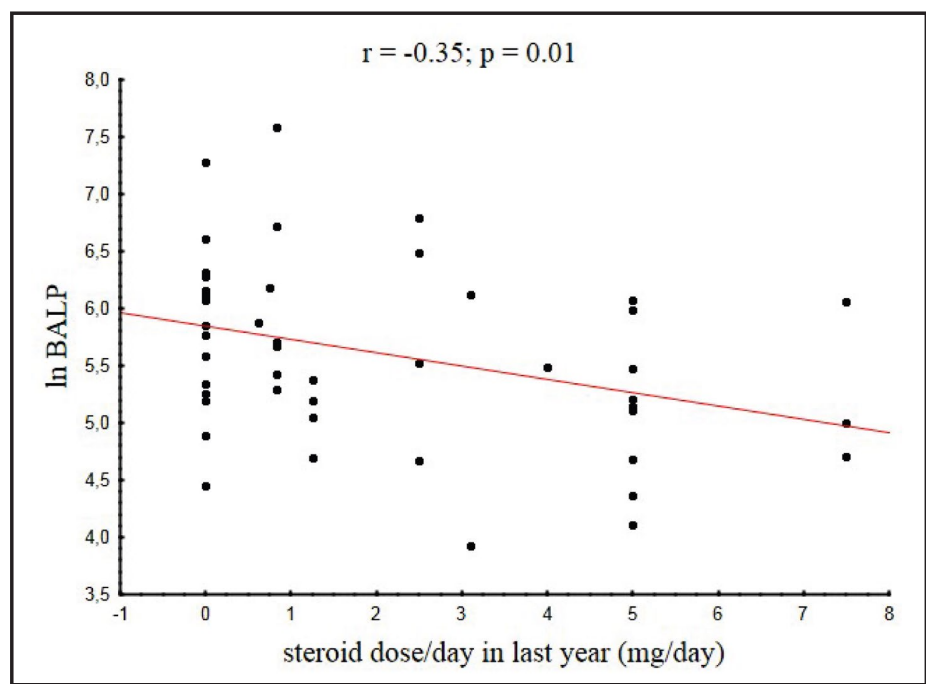

Fig. 1. Correlation between $\ln$ BALP and the daily steroid dose administered $(y=-0.11 * x+5.79)$.

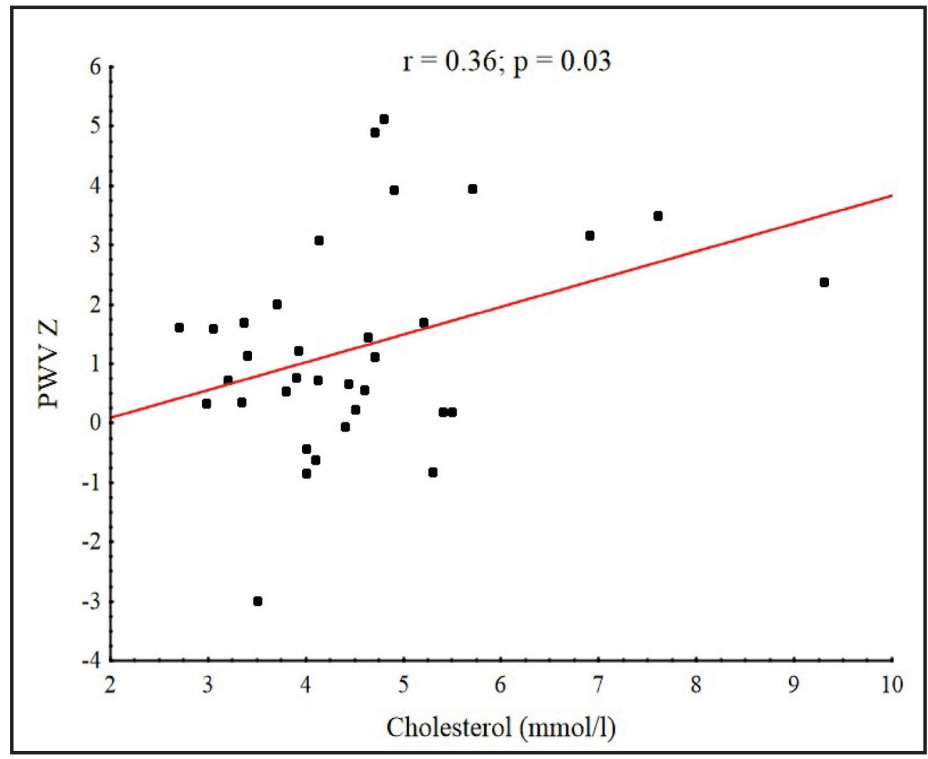

Fig. 2. Correlation between cholesterol and PWV-Z score in children transplanted $\geq 24$ months before $\left(y=0.45^{*} \mathrm{x}-0.87\right)$. 


\section{Kidney Blood Pressure Research}

Kidney Blood Press Res 2014;39:507-515

\begin{tabular}{l|l}
\hline DOI: $10.1159 / 000368461$ & (C) 2014 S. Karger AG, Basel
\end{tabular}

Publisned ontıne: November 28, 2014

www.karger.com/kbr

Cseprekál/Kis/Dégi/Kerti/Szabó/Reusz: Bone Metabolism and Arterial Stiffness Afte Renal Transplantation

Table 5. Follow-up of bone markers in 14 Tx children (between baseline and at 12 months)

\begin{tabular}{lcc}
\hline & initial data & $\begin{array}{c}\text { 12-month } \\
\text { follow-up }\end{array}$ \\
\hline Age (years) & $14.8(4.3)$ & $16.1(4.3)$ \\
PTH & $3.91(0.40)$ & $3.57(0.58)$ \\
In BALP/control & $1.34(0.38)$ & $0.44(0.69)^{*}$ \\
In OC/control & $1.39(0.36)$ & $0.45(0.80)^{*}$ \\
In beta-crosslaps/control & $1.27(0.31)$ & $0.56(0.67)^{*}$ \\
\hline * p <0.05; PTH: parathyroid hormone; BALP: bone alkaline \\
phosphatase; OC: osteocalcin; In: natural logarithm \\
\hline
\end{tabular}

The follow-up data of the fourteen children at 12-months follow-up are presented in Table 5. As can be seen, a significant decrease in BALP, OC and beta-crosslaps activity occurred over time.

\section{Discussion}

The present study used a series of biochemical markers and the measurement of pulse wave velocity in order to explore the relationship between bone metabolism and arterial stiffness in renal-transplanted children.

Since histological analysis of the iliac bone biopsy is not routinely performed, considerable efforts have been undertaken to develop reliable non-invasive methods to characterize bone turnover. As a result, a number of non-invasive markers are now available for clinical use representing different steps of bone metabolism [11, 20, 21].

In the present study, measurement of bone formation by BALP and OC was used as indicators of osteoblast activity [20]. Bone resorption is characterized by beta-crosslaps that have been shown to be more specific to bone resorption than any other currently available test [22]. Herein, the markers of bone formation and degradation were all closely interrelated, although only signifying that formation and degradation are indeed coupled processes.

The main results of the study are that a significantly increased activity of both bone formation and resorption was found, together with an increased arterial stiffness in patients after renal transplantation. Furthermore, BALP and OC were negatively correlated with mean steroid dose administered.

In the subgroup of patients with a one year follow-up, bone turnover decreased significantly, reflected by markers of both formation and degradation.

In parallel, during the two first years following transplantation, arterial stiffness was related to BALP and beta-crosslaps, whereas in patients transplanted longer than 2 years prior, serum cholesterol was the variable influencing PWV.

Previously, it was generally accepted that most patients who had received a renal graft during childhood had moderate to severe bone resorption and osteopenia even after many years following transplantation $[23,24]$. However, more recent data indicate that following successful transplantation, the initial increase in remodelling helps to correct the consequences of uremic vintage on the bone and after the second year following transplantation, bone mineral density (BMD) actually increases [11, 25-28]. Accordingly, to evaluate the effect of time since transplantation, patients were divided into two groups: those with a follow-up of less than 24 months, and those with a follow up of 24 months or longer.

Both bone remodelling and CV can be influenced by current kidney function, PTH levels and the effects of immunosuppressive drugs $[28,29]$. Indeed, cyclosporine and tacrolimus have been reported to increase both bone formation and resorption in the rat and to reduce bone volume [30,31]. Similar changes have also been described in adult and paediatric renal transplant recipients [32-34].

In the present study, immunosuppressive therapy was based on tacrolimus ( 40 patients) or cyclosporine (7 patients) and mycophenolate mofetil (all patients); twenty two patients 


\section{Kidney \\ Blood Pressure Research}

Kidney Blood Press Res 2014;39:507-515

\begin{tabular}{l|l}
\hline DOI: $10.1159 / 000368461$ & C 2014 S. Karger AG, Basel
\end{tabular}

Published onIIne: November 28, 2014

www.karger.com/kbr

received steroid therapy at the time of PWV measurement. Thus, calcineurine inhibitors likely account for the higher rates of bone formation in patients with normal serum iPTH levels, since prednisolone and other corticosteroids are usually associated with a decrease rather than an increase in bone formation and turnover [35]. During glucocorticoid therapy, levels of bone formation markers are generally low while those of bone resorption markers are either normal or low [36-38]. Presumably, the reduction in bone resorption is not sufficient to overcome the reduction in bone formation. This appears to be confirmed by the present finding showing a negative correlation between steroid treatment dose and BALP and OC, both markers of bone formation.

As expected, PWV was increased in the transplant group. As shown earlier, this increase is mainly the consequence of pre-transplantation uremic vintage, correlating with pretransplant $\mathrm{Ca}$ and phosphate values, the time spent on dialysis and the dose of vitamin $\mathrm{D}$ administered prior to transplantation [13, 19]. PWV may be influenced by hypertension. As the blood pressure of our patients was in normal range for age and height, we could not find any influence of blood pressure on PWV. In the present study, PWV was associated with the actual markers of bone turnover up to two years following transplantation, indicating a relationship between bone metabolism and the pathomechanism of arterial stiffening. Interestingly, in patients assessed more than two years following transplantation, this relationship was no longer present and the level of cholesterol was the independent determinant of PWV.

\section{Conclusion}

In summary, increased bone turnover and arterial stiffness can be observed in children following kidney tranplantation. While bone turnover decreases with time; arterial stiffness correlates initially with bone turnover whereas the influence of cholesterol becomes significant later on. Steroid administration is negatively correlated with arterial stiffness.

In conclusion, non-invasive estimation of bone metabolism and arterial stiffness may help to assess CKD-MBD in children following renal transplantation.

\section{Limitations}

This study has several limitations. The relatively low number of patients involved decreases the power of the conclusions. The predominantly cross-sectional nature of the study allows only to describe correlations but not causality. There are important factors influencing bone metabolism such as vitamin administration and FGF-23 levels that were not recorded or measured. In addition, evaluation of bone mineral density could have provided further information regarding bone status.

\section{Disclosure Statement}

The authors of this manuscript state that they do not have any conflict of interests and nothing to disclose.

\section{Acknowledgements}

Supported by OTKA 100909, MTA (HAS) postdoctoral fellowship and LP2011-008/2011 Lendulet Research Grant. 


\section{Kidney \\ Blood Pressure Research}

Kidney Blood Press Res 2014;39:507-515

\begin{tabular}{l|l}
\hline DOI: $10.1159 / 000368461$ & (C) 2014 S. Karger AG, Basel
\end{tabular}

Publisned ontIne: November 28, 2014

www.karger.com/kbr

\section{References}

1 Asci G, Ok E, Savas R, Ozkahya M, Duman S, Toz H, Kayikcioglu M, Branscum AJ, Monier-Faugere MC, Herberth J, Malluche HH: The link between bone and coronary calcifications in CKD-5 patients on haemodialysis. Nephrol Dial Transplant 2011;26:1010-1015.

-2 London GM, Marty C, Marchais SJ, Guerin AP, Metivier F, de Vernejoul MC: Arterial calcifications and bone histomorphometry in end-stage renal disease. J Am Soc Nephrol 2004;15:1943-1951.

3 London G, Coyne D, Hruska K, Malluche HH, Martin KJ: The new kidney disease: improving global outcomes (KDIGO) guidelines - expert clinical focus on bone and vascular calcification. Clin Nephrol 2010;74:423432 .

-4 Nemcsik J, Kiss I, Tislér A: Arterial stiffness, vascular calcification and bone metabolism in chronic kidney disease. World J Nephrol 2012;1:25-34.

5 Moe S, Drüeke T, Cunningham J, Goodman W, Martin K, Olgaard K, Ott S, Sprague S, Lameire N, Eknoyan G; Kidney Disease: Improving Global Outcomes (KDIGO): Definition, evaluation, and classification of renal osteodystrophy: a position statement from Kidney Disease: Improving Global Outcomes (KDIGO). Kidney Int 2006;69:1945-1953.

6 Fahrleitner-Pammer A, Herberth J, Browning SR, Obermayer-Pietsch B, Wirnsberger G, Holzer H, Dobnig $\mathrm{H}$, Malluche HH: Bone markers predict cardiovascular events in chronic kidney disease. J Bone Miner Res 2008;23:1850-1858.

7 Kalantar-Zadeh K, Molnar MZ, Kovesdy CP, Mucsi I, Bunnapradist S: Management of mineral and bone disorder after kidney transplantation. Curr Opin Nephrol Hypertens 2012;21:389-403.

-8 Weisinger JR, Carlini RG, Rojas E, Bellorin-Font E: Bone disease after renal transplantation. Clin J Am Soc Nephrol 2006;1:1300-1313.

-9 Wesseling-Perry K, Bacchetta J: CKD-MBD after kidney transplantation. Pediatr Nephrol 2011;26:21432151.

10 Delanaye P, Souberbielle JC, Lafage-Proust MH, Jean G, Cavalier E: Can we use circulating biomarkers to monitor bone turnover in CKD haemodialysis patients? Hypotheses and facts. Nephrol Dial Transplant 2013;29:997-1004.

11 Reusz GS, Szabó AJ, Péter F, Kenesei E, Sallay P, Latta K, Szabó A, Szabó A, Tulassay T: Bone metabolism and mineral density following renal transplantation. Arch Dis Child 2000;83:146-151.

12 O'Rourke MF, Mancia G: Arterial stiffness. J Hypertens 1999;17:1-4.

-13 Cseprekál O, Kis E, Schäffer P, Othmane Tel H, Fekete BC, Vannay A, Szabó AJ, Remport A, Szabó A, Tulassay T, Reusz GS: Pulse wave velocity in children following renal transplantation. Nephrol Dial Transplant 2009;24:309-315.

$\checkmark 14$ Evenepoel P: Recovery versus persistence of disordered mineral metabolism in kidney transplant recipients. Semin Nephrol 2013;33:191-203.

15 Soergel M, Kirschstein M, Busch C, Danne T, Gellermann J, Holl R, Krull F, Reichert H, Reusz GS, Rascher W: Oscillometric twenty-four-hour ambulatory blood pressure values in healthy children and adolescents: a multicenter trial including 1141 subjects. J Pediatr 1997;130:178-184.

16 Salvi P, Lio G, Labat C, Ricci E, Pannier B, Benetos A: Validation of a new non-invasive portable tonometer for determining arterial pressure wave and pulse wave velocity: the PulsePen device. J Hypertens 2004;22:2285-2293.

17 Reusz GS, Cseprekal O, Temmar M, Kis E, Cherif AB, Thaleb A, Fekete A, Szabó AJ, Benetos A, Salvi P: Reference values of pulse wave velocity in healthy children and teenagers. Hypertension 2010;56:217-224.

-18 Schwartz GJ, Brion LP, Spitzer A: The use of plasma creatinine concentration for estimating glomerular filtration rate in infants, children, and adolescents. Pediatr Clin North Am 1987;34:571-590.

19 Kis E, Cseprekál O, Bíró E, Kelen K, Ferenczi D, Kerti A, Szabó AJ, Szabó A, Reusz GS: Effects of bone and mineral metabolism on arterial elasticity in chronic renal failure. Pediatr Nephrol 2009;24:2413-2420.

20 Borchhardt K, Sulzbacher I, Benesch T, Födinger M, Sunder-Plassmann G, Haas M: Low-turnover bone disease in hypercalcemic hyperparathyroidism after kidney transplantation. Am J Transplant 2007;7:25152521.

21 Waller S, Ridout D, Rees L: Effect of haemodialysis on markers of bone turnover in children. Pediatr Nephrol 2007;22:586-592. 


\section{Kidney \\ Blood Pressure Research}

Cseprekál/Kis/Dégi/Kerti/Szabó/Reusz: Bone Metabolism and Arterial Stiffness After Renal Transplantation

22 Negri AL, Quiroga MA, Bravo M, Marino A, Fradinger E, Bogado CE, Zanchetta JR: Serum crosslaps as bone resorption marker in peritoneal dialysis. Perit Dial Int 2002;22:628-630.

23 Chesney RW, Rose PG, Mazess RB: Persistence of diminished bone mineral content following renal transplantation in childhood. Pediatrics 1984;73:459-466.

-24 Boot AM, Nauta J, Hokken-Koelega AC, Pols HA, de Ridder MA, de Muinck Keizer-Schrama SM: Renal transplantation and osteoporosis. Arch Dis Child 1995;72:502-506.

-25 Schönau E, Wentzlik U, Michalk D, Scheidhauer K, Klein K: Is there an increase of bone density in children? Lancet 1993;342:689-690.

-26 Klaus G, Paschen C, Wüster C, Kovacs GT, Barden J, Mehls O, Schärer K: Weight-/height-related bone mineral density is not reduced after renal transplantation. Pediatr Nephrol 1998;12:343-348.

-27 Feber J, Cochat P, Braillon P, Castelo F, Martin X, Glastre C, Chapuis F, David L, Meunier PJ: Bone mineral density after renal transplantation in children. J Pediatr 1994;125:870-875.

28 Falkiewicz K, Boratyńska M, Zmonarski SC, Milewicz A, Patrzałek D, Biecek P, Klinger M: Evolution of bone disease at 2 years after transplantation: a single-center study. Transplant Proc 2009;41:3063-3066.

29 Liefeldt L, Budde K: Risk factors for cardiovascular disease in renal transplant recipients and strategies to minimize risk. Transpl Int 2010;23:1191-1204.

-30 Cvetkovic M, Mann GN, Romero DF, Liang XG, Ma Y, Jee WS, Epstein S: The deleterious effects of longterm cyclosporine A, cyclosporine G, and FK506 on bone mineral metabolism in vivo. Transplantation 1994;57:1231-1237.

-31 Abdelhadi M, Ericzon BG, Hultenby K, Sjöden G, Reinholt FP, Nordenström J: Structural skeletal impairment induced by immunosuppressive therapy in rats: cyclosporine A vs tacrolimus. Transpl Int 2002;15:180187.

-32 Marcen R, Caballero C, Pascual J, Teruel JL, Tenorio M, Ocana J, Villafruela JJ, Burgos FJ, Fernandez AM, Muriel A, Ortuno J: Lumbar bone mineral density in renal transplant patients on neoral and tacrolimus: a four-year prospective study. Transplantation 2006;81:826-831.

-33 Cueto-Manzano AM, Konel S, Hutchison AJ, Crowley V, France MW, Freemont AJ, Adams JE, Mawer B,Gokal R: Bone loss in long-term renal transplantation: histopathology and densitometry analysis. Kidney Int 1999;55:2021-2029.

-34 Sanchez CP, Salusky IB, Kuizon BD, Ramirez JA, Gales B, Ettenger RB, Goodman WG: Bone disease in children and adolescents undergoing successful renal transplantation. Kidney Int 1998;53:1358-1364.

-35 Molnar MZ, Naser MS, Rhee CM, Kalantar-Zadeh K, Bunnapradist S: Bone and mineral disorders after kidney transplantation: Therapeutic strategies. Transplant Rev (Orlando) 2014;28:56-62.

-36 Ebeling PR, Erbas B, Hopper JL, Wark JD, Rubinfeld AR: Bone mineral density and bone turnover in asthmatics treated with long-term inhaled or oral glucocorticoids. J Bone Miner Res 1998;13:1283-1289.

-37 Siomou E, Challa A, Tzoufi M, Papadopoulou ZL, Lapatsanis PD, Siamopoulou A: Biochemical markers of bone metabolism in infants and children under intravenous corticosteroid therapy. Calcif Tissue Int 2003;73:319-325.

-38 Ahmed SF, Tucker P, Mushtaq T, Wallace AM, Williams DM, Hughes IA: Short-term effects on linear growth and bone turnover in children randomized to receive prednisolone or dexamethasone. Clin Endocrinol (Oxf) 2002;57:185-191. 